\title{
Zener Relaxation in Al-Li Binary Alloys
}

\author{
J.I. Pérez-Landazábal, M.L. Nó* and J. San Juan \\ Dpto. Física Materia Condensada, Fac. Ciencias U.P.V., Apdo. 644, 48080 Bilbao, Spain \\ *Dpto. Física Aplicada II, Fac. Ciencias U.P.V., Apdo. 644, 48080 Bilbao, Spain
}

\begin{abstract}
Internal friction (I.F.) and modulus measurements have been carried out as a function of temperature in order to study the Li mobility in an $\mathrm{Al}-8.1$ at $\% \mathrm{Li}-0.03$ at $\% \mathrm{Zr}$ alloy. The results show that the sequence of $\delta^{\prime}$ and $\delta$ precipitation can be followed through the evolution of the internal friction spectra. Two peaks appear in the internal friction spectrum. The low temperature peak $\mathrm{Pz}(450 \mathrm{~K})$, has associated a dynamic modulus defect, an activation energy of $1.2 \mathrm{eV}$ and the width of a Debye peak. The analysis of the behaviour of this relaxation allows us to identify the $\mathrm{Pz}$ peak with the Zener relaxation process. The relaxation parameters lead us to determine the activation energy and the diffusion coefficient of $\mathrm{Li}$ in Aluminium.
\end{abstract}

\section{INTRODUCTION}

Aluminium-Lithium alloys have shown to be very useful as alternative materials in aerospace industries. This capability has been achieved with quaternary $\mathrm{Al}-\mathrm{Li}-\mathrm{Cu}-\mathrm{Mg}$ alloys. Nowadays, there exist commercial Al-Li alloys that fit appropriately important mechanical requirements [1]. It is know that mechanical properties are directly related to the microstructural state of the alloy, but the complexity of the precipitation processes that take place in these commercial alloys has lead us to begin with easier systems. Since $\mathrm{Al}-\mathrm{Cu}$ [2-6] and Al-Mg [6-10] have been extensively studied, we have centred our attention in the Al-Li system where there exist very few works using anelastic techniques [11-13]. The microstructural evolution of these alloys could be described as follows (see [14] for a review). After quenching, the solid solution $\alpha$ decomposes in the metastable and coherent $\delta^{\prime}$ phase that nucleates homogeneously through the matrix. Subsequent ageing produces the precipitation growth but keeping the spherical shape on for very long ageing times. Finally this phase transforms to the stable $\delta$ phase at low and high angle grain boundaries. Then, the sequence can be written as: $\alpha$ (S.S.S.) $\rightarrow \alpha_{1}+\delta^{\prime} \rightarrow \alpha_{2}+\delta$.

In this work, we have studied the precipitation of the binary Al-Li system through the evolution of the I.F. spectrum and the dynamical modulus change.

\section{EXPERIMENTAL PROCEDURE}

We have used an Al-2.25 wt \% Li-0.1 wt $\% \mathrm{Zr}$ alloy supplied by Pechiney as an extruded plate with the T3 treatment. The samples were cut from this plate on $50 \times 5 \times 1 \mathrm{~mm}$ plates perpendicular to the extrusion direction, solution treated at $530^{\circ} \mathrm{C}$ for $30 \mathrm{~min}$ in a salt bath and quenched into iced water. The samples were subsequently mechanically polished to eliminate an external layer $0.1 \mathrm{~mm}$ thick, because of the loss of lithium at the surface during the solution treatment [15].

The I.F. and resonance frequency measurements were carried out in an inverted torsion pendulum working at $1 \mathrm{~Hz}$ [16]. The measurements were performed in the range $150 \mathrm{~K}$ to $640 \mathrm{~K}$ and the oscillating amplitude was changed from $1 \times 10^{-6}$ to $7.5 \times 10^{-5}$. The temperature rate was varied from $60 \mathrm{~K} / \mathrm{h}$ to $180 \mathrm{~K} / \mathrm{h}$. The resonance frequency can be controlled changing the pendulum inertia or the sample thickness. 


\section{RESULTS AND DISCUSSION}

The I.F. spectrum and square resonance frequency curve obtained after solid solution treatment is shown in figure 1.

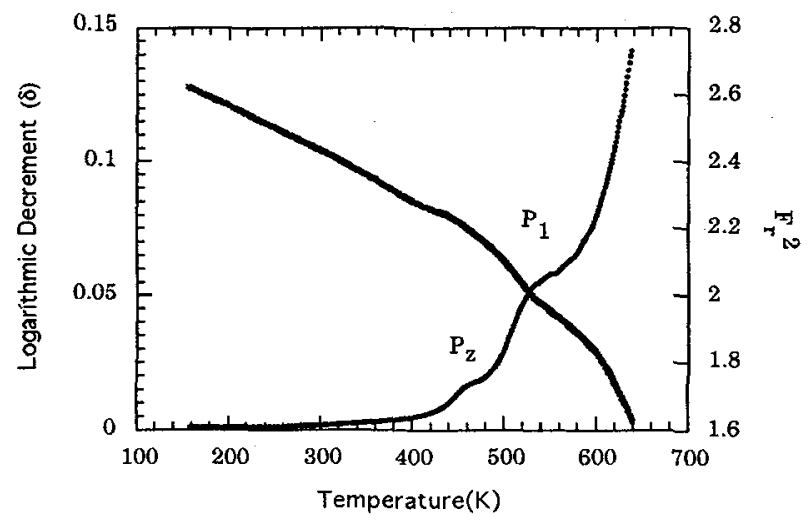

Figure 1: Temperature dependence of the internal friction $(\bullet)$ and squared resonance frequency $(x)$.

The I.F. curve shows the presence of two peaks superimposed to a high temperature background: A low temperature peak $\left(\mathrm{P}_{\mathrm{z}}\right)$ at around $460 \mathrm{~K}$ and a high temperature peak $\left(\mathrm{P}_{1}\right)$ at around $540 \mathrm{~K}$. The $\mathrm{P}_{\mathrm{z}}$ peak is associated with an increase in the modulus and the $\mathrm{P}_{1}$ with an initial decrease followed by an increase in the modulus. In order to remove the background we have followed the method described by Nowick [17] and Nó [18]. Figure 2 shows the peaks obtained after background subtraction following this procedure, that are perfectly reproducible in different measurements [15]..

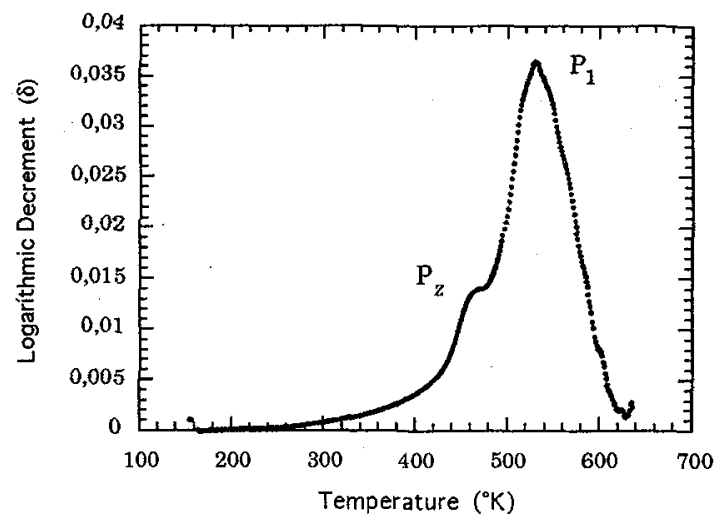

Figure 2: $P_{Z}$ and $P_{1}$ peaks obtained after background subtraction.

To compare the influence of the microstructural state of the alloy on the internal friction spectrum we performed the same measurements successively without dismounting the sample from the pendulum. The difference between the first and second cycle can be seen in figure 3 . The phases present and their distributions at the beginning of the second heating run are different from those in the first cycle due to the precipitation process that take place during the first heating run. 


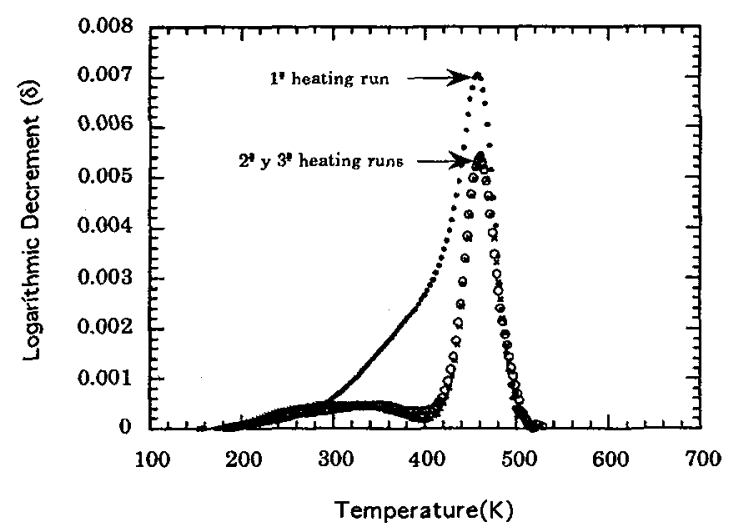

Figure 3: Evolution of the I.F. spectra for three consecutive heating runs.

In a previous work [19] we have shown that the relaxation strength of the Pz peak reduces when the precipitated $\delta^{\prime}$ fraction increases and that the strength of the peak is sensitive to the texture of the sample. Besides, the $P_{\mathbf{Z}}$ relaxation has been shown to be amplitude independent [15] indicating that the process has an activation volume of atomic size. This behaviour seems to indicate that this peak can be associated to an atomic process related to the solid solution of aluminium.

The variation of the temperature of the peak maximum with the resonance frequency has led to an activation energy $\mathrm{E}_{\mathrm{a}}=1.2 \pm 0.1 \mathrm{eV}$ and to a limiting relaxation time $\tau_{\mathrm{o}}=4.510^{-14} \mathrm{~s}$ (fig.3). The value of $\mathrm{E}_{\mathrm{a}}$ corresponds to the activation energy of lithium diffusion through the Al lattice. Then, we expect that this relaxation is linked to $\mathrm{Li}$ diffusion. The relaxation time leads to the $\mathrm{Li}$ diffusion coefficient $: \mathrm{D}=0.003$ $\exp (-1.2 \mathrm{eV} / \mathrm{kT}) \mathrm{cm}^{2} / \mathrm{s}$, which agrees with other results [15].

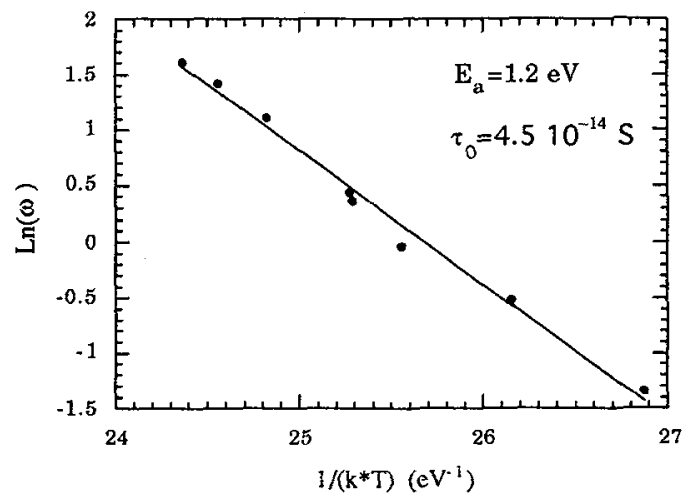

Figure 4: Arrhenius plot of the peak maximum datá (ln $(\omega)$ versus $1 / k T)$ to obtain the activation energy $\left(\mathrm{E}_{\mathrm{a}}\right)$ and the characteristic relaxation time $\left(\tau_{0}\right)$.

The experimental characteristics of the $\mathrm{P}_{z}$ peak allow us to identify this peak with the Zener relaxation due to the stress induced reorientation of $\mathrm{Li}-\mathrm{Li}$ pairs. In this case the relaxation is expected to behave, in a first approximation [17], as a Debye peak, which is in agreement with our experimental results as it can be seen in figure 5. 


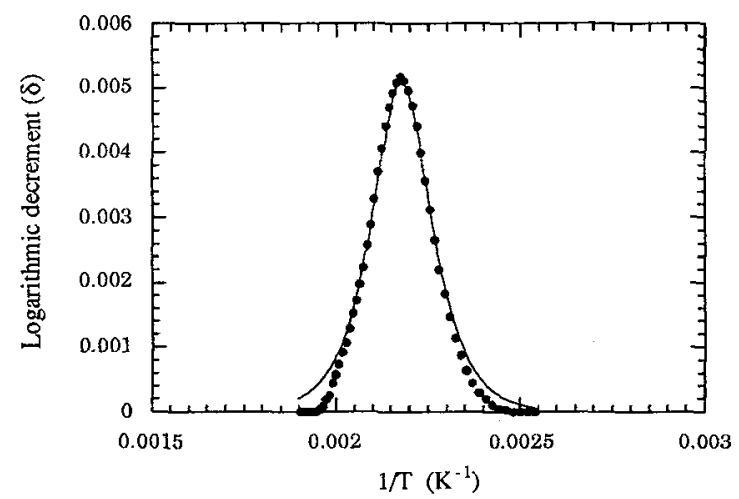

Figure 5: Logarithmic decrement $(\delta)$ during the second heating run versus $1 / \mathrm{T}$ (black dots) and Debye peak fitting (continuous line)

\section{CONCLUSIONS}

The I.F. peak $P_{Z}$ occurring at around $460 \mathrm{~K}(\sim 1 \mathrm{~Hz})$ has the activation energy, activation volume and relaxation time characteristic of $\mathrm{Li}$ diffusion in aluminium. Reduction in the number of $\mathrm{Li}-\mathrm{Li}$ pairs (precipitation of $\delta^{\prime}$ ) reduces relaxation strength. The peak shows the characteristics of a Debye peak. Then we conclude that the Li-Li Zener peak has been identified $\left(\mathrm{P}_{\mathrm{Z}}\right.$ Peak) and characterised in Al-Li alloys.

\section{Acknowledgements}

This work has been carried out with the financial support of the Spanish "Comision Interministerial de Ciencia y Tecnología" (CICyT) in the framework of the "Plan Nacional de Materiales" (Project number MAT 89-0554-C02-02). Perez-Landazábal wishes to acknowledge the Basque Country Government for providing him a postgraduate grant. The authors wish also to thank the Pechiney Company for supplying the alloy.

\section{References}

[1] C.J. Peel, New Light alloys, Lecture serie No 174 AGARD - NATO (1990) p.1-1

[2] B.S. Berry, Acta Met., 9 (1961) 98.

[3] C. Hanauer, J. Merlin, J. Pérez, Mém. Sci. Rev. Met. 69 (1972) 653.

[4] S. Kiss, F.J. Kedves, I.Z. Harangozo, Nuovo Cimento, 33B (1976) 380.

[5] F. Fouquet, P. Merle, M. Kohen et Al., Acta Met., 27 (1979) 315.

[6] R. Schaller, W. Benoit, J. de Phys., C9 (1983) 17.

[7] W.G. Nilson, Can. J. Phys. 39 (1961) 119.

[8] B.N. Dey, M.A. Quader, Can. J. Phys. 43 (1965) 1347.

[9] J. Belson, D. Lemercier, P. Moser, P. Vigier, Phys. Stat. Sol., 40 (1970) 647.

[10] J. Othmezouri-Decerf, J. de Phys., C9 (1983) 265.

[11] J. Pérez-Landazábal, J. San Juan, M.L. Nó, Sixth International Aluminium-Lithium Conference, Garmisch-Partenkirchen, Germany, 1991, M.Peters, P.J. Winkler Eds. p.143.

[12] Z.Q. Zhou, Mei Li, C.Q. Chen, Sixth International Aluminium-Lithium Conference, M.Peters, P.J. Winkler Eds. Garmisch-Partenkirchen, Germany, 1991), p.463.

[13] Q.Tan, Z.Q. Zhou, Sixth International Aluminium-Lithium Conference, Garmisch-Partenkirchen, Germany, 1991, M.Peters, P.J. Winkler Eds. p.475.

[14] E. A. Starke Jr., W. E. Quist, New light alloys, Lecture serie № 174 AGARD - NATO (1990) p.2-1

[15] J. Pérez-Landazábal, Ph.D. Thesis. Univ. Pais Vasco, Bilbao, Spain (1995)

[16] A. Oleaga, I. Hurtado, M.L. Nó, C. Esnouf, J. San Juan, Anales de Física $85 B$ (1989), 373

[17] A.S. Nowick, B.S. Berry, Anelastic relaxation in cristalline solids, Mat. Science Series, (1972)

[18] M.L. Nó, Ph.D. Thesis. Univ. Bilbao, Pais Vasco, Spain (1990)

[19] J. Pérez-Landazábal, M.L. Nó, , J. San Juan, Appl. Phys. Lett. 67, (1995), 1200. 